\title{
Dificuldades e Sucessos de Professores de EducaÇão Física em RelaÇão À INCLUSÃo ESCOLAR ${ }^{1}$ \\ Difficulties and SucCesses Physical EDUCATION TEACHers EXPERIENCE With SCHOOL INCLUSION
}

\author{
Maria Luiza Salzani FIORINI² \\ Eduardo José MANZINI ${ }^{3}$
}

\begin{abstract}
RESUMO: objetivou-se identificar as situaçôes de dificuldade e as situaçôes de sucesso de dois professores de Educação Física, em turmas regulares em que há alunos com deficiência e alunos com autismo matriculados, para subsidiar o planejamento de uma formação continuada. Os participantes foram dois professores de Educação Física que atuavam em Escola Municipal de Ensino Fundamental, do $1^{\circ}$ ao $5^{\circ}$ ano, de uma cidade da regiāo Centro-Oeste do Estado de São Paulo. Realizaram-se filmagens de 12 aulas de P1 e 16 aulas de P2. As filmagens foram categorizadas em temas. Para P1 foram identificados três temas: situações de sucesso, dificuldade relacionada à estratégia, e a falta de ação propositiva em relação à inclusão. Para P2 foram identificados sete temas: situaçôes de sucesso e dificuldades relacionadas à seleção do conteúdo, à estratégia de ensino, ao recurso pedagógico, às características dos alunos, à falta de ação propositiva em relação à inclusão e possibilidades e dificuldades relacionadas à presença da professora de sala na Educação Física. Conclui-se que, os dois professores encontravam dificuldades para incluir os alunos com deficiência e alunos com autismo, mas eles também vivenciavam situaçôes de sucesso. As filmagens permitiram um detalhamento das necessidades dos professores e o entendimento de que a formação continuada deveria ser desenvolvida no sentido de, considerar o contexto das aulas, auxiliar na minimização das dificuldades e valorizar as açóes de sucesso.
\end{abstract}

PALAVRAS-CHAVE: Educação Especial. Educação Física. Tecnologia Assistiva. Inclusão Escolar.

\begin{abstract}
The objective of this study was to identify situations of difficulty and success of the two physical education teachers during regular classes with students with disabilities and students with autism to subsidize a plan for a Continuing Education. The participants were two physical education teachers who worked in an Elementary School, from the first to the fifth grades, in a city of the Midwest region in Sáo Paulo State. Twelve T1 classes and sixteen T2 classes were video recorded. The recordings were categorized into themes. For T1, three themes were identified: successful situations; difficulties related to the strategy; and the lack of purposeful action in relation to inclusion. For T2, seven themes were identified: situations of success and difficulties related to content selection, teaching strategy, teaching resources, the students' characteristics, lack of purposeful action in relation to inclusion and possibilities and difficulties related to the presence of the classroom teacher during the Physical Education class. It was concluded that the two teachers found it difficult to include students with disabilities and students with autism in the class, but they were also experiencing successful situations. The recordings allowed detailing the needs of teachers and understanding that Continuing Education should be developed in order to consider the context of the classes and to assist in minimizing the difficulties and enhancing the successful actions.
\end{abstract}

KEYWORDS: Special Education. Physical Education. Assistive Technology. School Inclusion.

\section{INTRODUÇÁ̃o}

Para entender as necessidades de formação de professores frente à inclusão escolar de alunos com deficiência e alunos com autismo são necessárias pesquisas que identifiquem as

\footnotetext{
${ }^{1}$ Apoio: CAPES/CNPq Processo 402016/2011-4; Processo FAPESP 2012/13075-6 http://dx.doi.org/10.1590/S1413-65382216000100005

${ }^{2}$ Doutora em Educação, Universidade Estadual Paulista, Unesp, campus de Marília. Marília, SP, Brasil. salzanifiorini@yahoo. com.br

${ }^{3}$ Docente do Departamento de Educação Especial e do Programa de Pós-Graduação em Educação, Unesp, campus de Marília. Marília, SP, Brasil.manzini@marilia.unesp.br
} 
carências e lacunas na formação profissional (MANZINI, 2011). Tendo como pano de fundo o planejamento de uma formação continuada para professores de Educação Física visando a inclusão escolar, tem-se como problema de pesquisa: quais as dificuldades e os sucessos encontrados por professores de Educação Física em turmas regulares em que há alunos com deficiência e alunos com autismo?

A construção de uma escola numa perspectiva inclusiva é um dos grandes desafios dos sistemas educacionais (MARTINS, 2012). A inclusão escolar de alunos com deficiência e alunos com autismo tem conduzido os espaços escolares a construírem novas lógicas de ensino (JESUS; EFFGEN, 2012). Espera-se que, principalmente os professores, modifiquem a forma tradicional de "olhar" o diferente, de modo que "enxerguem" as capacidades e as potencialidades, ou seja, não se pode mais "olhar" para os alunos e "ver", por exemplo, trinta mais um (o diferente) e sim 31 alunos (NABEIRO, 2010). Com o foco na inclusão escolar em aulas regulares de Educação Física, torna-se necessário, também, pensar em múltiplas formas de trabalhar a Educação Física, identificando e atendendo as diferenças (RECHINELI; PORTO; MOREIRA, 2008). Mas, como essa reestruturação no modo de olhar para os alunos com deficiência e alunos com autismo, e de conceber a própria Educação Física poderia fazer parte do dia a dia do professor? Quais deveriam ser as características das aulas nessa perspectiva?A partir de um levantamento realizado na literatura nacional e internacional foram identificados elementos que auxiliarão a responder essas questóes.

Por um lado, se reconhece que a responsabilidade de criar condições favoráveis à inclusão de alunos com deficiência e os alunos com autismo nas aulas regulares de Educação Física não é competência exclusiva do professor (ALVES; DUARTE, 2014). Por outro lado, acredita-se que a transformação nas atitudes seja primordial para uma prática favorável à inclusão (PALLA; MAUERBERG-DE CASTRO, 2004). Pesquisas indicaram que professores de Educação Física, com atitude positiva para a inclusão, foram mais eficazes do que os professores com atitude negativa, pois forneceram mais prática e em alto nível de sucesso (DUPOUX; WOLMAN; ESTRADA, 2005; ELLIOTT, 2008).

Outra recomendaçáo é que o professor esteja ciente de que incluir nas aulas de Educação Física não é simplesmente adaptar a disciplina, mas é adotar uma perspectiva educacional que valorize a diversidade e seja comprometida com a construção de uma sociedade inclusiva (CHICON, 2005). Para tanto, é indispensável planejar a aula de modo anão se restringir à condição das pessoas envolvidas, mas promover a autonomia e enfatizar o potencial dos alunos (MUNSTER; ALMEIDA, 2006; CHICON; MENDES; SÁ, 2011). É parte integrante do planejamento: os objetivos, os conteúdos e as atividades, as adaptaçóes, os procedimentos de ensino e os recursos (SANT'ANNA et al., 1998). Sobre os objetivos, uma vez definidos, o professor deverá modificá-los apenas quando necessário, em respeito à individualidade e às habilidades dos alunos (PEDRINELLI; VERENGUER, 2004).

Com relação ao currículo, ele não necessariamente se diferencia em conteúdos, mas, compreende técnicas, formas de organização e adaptaçóes específicas para atender às necessidades dos alunos (BUENO; RESA, 1995). Para Gorgatti (2005), a adaptação curricular pode ocorrer em nível da escola, da turma ou do aluno. Além disso, Craft (1996) sugeriu outras opçóes: 1) currículo único para alunos com e sem deficiência; 2) os alunos desenvolvem a mes- 
ma unidade temática, mas com objetivo e nível distinto; 3) os alunos desenvolvem a mesma unidade temática, mas praticam atividade diferente ou adaptada e, 4) currículo alternativo. Associadas ao currículo estão as atividades. Estudos indicaram que conteúdos competitivos dificultaram a inclusão por aguçarem a atitude negativa dos alunos sem deficiência (BEZERRA, 2010; FIORINI, 2011), e que as atividades de execução individual apresentavam menos obstáculos à inclusão (MORLEY et al., 2005). Outros estudos sugeriram atividades favoráveis à inclusão como, físicas, recreativas e esportivas (LIEBERMAN; HOUSTON - WILSON, 2002; MUNSTER; AVERSAN, 2011), jogos cooperativos (OLIVEIRA, 2009) e jogos e brincadeiras populares (CHICON, 2005).

Mais um ponto a ser considerado pelo professor de Educação Física se refere à maneira de apresentar um conteúdo, com atenção à seleção e modificação de estilos de ensino que proporcionem os maiores benefícios educacionais a todos os alunos (WINNICK, 2004).

Outro elemento constituinte do planejamento é a adaptação. Algumas atividades só se tornam acessíveis às pessoas com deficiência mediante a realização de adaptaçôes (MUNSTER; ALMEIDA, 2006). Adaptar é ajustar a tarefa ao nível de desempenho da pessoa (WINNICK, 2004) e pode ocorrer por meio do manejo de variáveis, como: os ambientes temporal, físico e psicossocial, os equipamentos e materiais, a instrução, a tarefa e a regra (SHERRIL, 1998; LIEBERMAN; HOUSTON - WILSON, 2002; WINNICK, 2004; BEZERRA, 2010).

Ainda sobre as adaptações, Munster (2013) sugeriu quatro combinações entre adaptaçóes curriculares e metodológicas, sendo elas: 1) conteúdo convencional e recursos e estratégias usuais; 2) conteúdo convencional e recursos e estratégias diferenciadas; 3) conteúdo alternativo e recursos e estratégias adequados e, 4) conteúdo adaptado e recursos e estratégias específicos. A autora referiu-se a dois termos que são essenciais no planejamento e no desenvolvimento de aulas de Educação Física: estratégias e recursos. Ambos os conceitos fazem parte da Tecnologia Assistiva, definida pelo Comitê Nacional de Ajudas Técnicas com vistas à realidade brasileira como:

[...] uma área do conhecimento, de característica interdisciplinar, que engloba produtos, recursos, metodologias, estratégias, práticas e serviços que objetivam promover a funcionalidade, relacionada à atividade e participação, de pessoas com deficiência, incapacidades ou mobilidade reduzida, visando sua autonomia, independência, qualidade de vida e inclusão social (BRASIL, 2007).

Por estratégia de ensino, encampa-se a definição de Manzini (2010, p.14), em que a estratégia pode ser concebida como toda ação do professor em relação ao recurso pedagógico ou em relação ao aluno:

[...] que acontece no momento do ensino ou da avaliação do aluno. Porém, deve ser planejada anteriormente, levando em consideraçáo as características da deficiência, as potencialidades do aluno, o objetivo que se pretende com a realizaçáo da atividade e o nível de complexidade da atividade exigida.

A estratégia é flexível e passível de ser modificada caso o professor a identifique como não funcional para o aluno, por isso, é indispensável planejar mais de uma estratégia para cada atividade (MANZINI, 2010). Quanto ao recurso pedagógico, adota-se a definição de Manzini 
(1999) e Manzini e Deliberato (2007) que o conceituaram como um estímulo concreto, manipulável e com uma ou mais finalidades pedagógicas.

Dessa forma, pode-se pensar em estratégias de ensino de Tecnologia Assistiva e recursos pedagógicos de Tecnologia Assistiva. Para que a estratégia de ensino e o recurso pedagógico possam ser enquadrados como Tecnologia Assistiva, ambos devem ser funcionais ao aluno no que se refere à atividade e participação, visando a autonomia e independência. Não basta ater-se apenas à estratégia ou ao recurso. É necessário que a estratégia ou o recurso seja usado funcionalmente pela pessoa com deficiência ou com autismo (MANZINI; ALBUQUERQUE, 2014, no prelo).

Destaca-se que, também foi identificada na literatura a necessidade de espaço físico adequado e acessível (RIZZO; LAVAY, 2000; GORGATTI, 2005), e o papel da equipe gestora da escola que poderia oferecer suporte aos professores (PILETTI, 2014).

Adotando-se como parâmetro as fundamentações apresentadas, têm-se como objetivo do presente estudo: identificar as situaçôes de dificuldade e as situações de sucesso de dois professores de Educação Física, nas turmas regulares em que há alunos com deficiência e alunos com autismo matriculados, para subsidiar o planejamento de uma formação continuada.

\section{Método}

O presente estudo configura-se como uma pesquisa qualitativa-descritiva, de natureza observacional, por meio do registro em filmagem de aulas de Educação Física. A construção dos dados e as análises fundamentaram-se na pesquisa reflexiva e colaborativa para a formação de professores (PIMENTA, 2005; MENDES; TOYODA, 2008; MENDES, 2008; JESUS, 2008a, 2008b).

Cabe aqui esclarecer que se trata de um recorte de um estudo maior, o qual objetivou planejar, aplicar e avaliar um programa de formação continuada para professores de Educação Física visando a inclusão. Este manuscrito retrata, especificamente, a segunda etapa dessa pesquisa. Em etapa anterior, por meio da realização de encontros de Grupo Focal, com a participação de 17 professores de Educação Física, foram identificadas as dificuldades relatadas por esses professores para atender a demanda da inclusão escolar. Os resultados das duas etapas subsidiaram o planejamento da formação continuada.

\subsection{Participantes}

Os participantes foram dois professores de Educação Física que atuavam em Escola Municipal de Ensino Fundamental (EMEF), do $1^{\circ}$ ao $5^{\circ}$ ano, de uma cidade da região CentroOeste do Estado de São Paulo. A seleção dos professores ocorreu a partir de dois critérios: 1) deveria ter participado da primeira etapa da pesquisa; 2) precisava ser voluntário, permitir que as suas aulas fossem filmadas e ter interesse em atuar com Tecnologia Assistiva.

Dentre os 17 professores que participaram da primeira etapa da pesquisa e, por isso, atendiam ao primeiro critério, nove se voluntariaram. Para definir os participantes recorreu-se aos resultados de um Estudo Preliminar sobre a matrícula de alunos com deficiência e alunos com autismo em EMEF do município em questão, o qual indicou que a EMEF 16, situada na região Norte, tinha o número mais elevado de matrículas de alunos com deficiência e alunos com autismo. 
Dentre os nove professores voluntários, dois (P1 e P2) eram professores da EMEF 16, um em cada período e, individualmente, ministravam aulas para o maior número de alunos com deficiência e alunos com autismo, quando comparados aos demais voluntários. Deste modo, foram selecionados os dois professores: o da manhã (P1) e o da tarde (P2).

\subsection{Coleta dos dados}

As aulas de Educação Física foram registradas por meio de filmagem, tendo sido realizados quatro registros por turma, com base nos indicativos de pesquisas anteriores (BEZERRA, 2010; FIORINI; NABEIRO, 2013). Ao todo foram filmadas 28 aulas, sendo 12 aulas de P1 e 16 aulas de $\mathrm{P} 2$.

As turmas foram selecionadas a partir de três critérios: 1) deveria ter um ou mais alunos com deficiência ou alunos com autismo matriculado; 2) deveria ser a turma que, segundo o relato do professor de Educação Física, gerava dificuldade para incluir; 3) o professor poderia convidar para que fosse registrado o que ele relatava como "sem dificuldade para incluir".

Com base nos critérios foram selecionadas três turmas do período da manhã e quatro turmas do período da tarde, como descrito no Quadro 1.

\begin{tabular}{|l|l|}
\hline No período da manhã - P1 & No período da tarde - P2 \\
\hline $\begin{array}{l}1^{\circ} \text { ano, aluno com Síndrome de Tourette/dificuldade } \\
\text { de comportamento }\end{array}$ & $1^{\circ}$ ano, aluno com autismo \\
\hline $\begin{array}{l}5^{\circ} \text { ano, aluno com paralisia cerebral que usava cadei- } \\
\text { ra de rodas, tinha controle postural e tinha movi- } \\
\text { mentação nos membros inferiores e superiores }\end{array}$ & $\begin{array}{l}1^{\circ} \text { ano, um aluno com autismo/paralisia cerebral/Síndro- } \\
\text { me de Dand Walker }\end{array}$ \\
\hline $\begin{array}{l}2^{\circ} \text { ano, aluno com atraso no desenvolvimento neu- } \\
\text { ropsicomotor e utilizava um andador }\end{array}$ & $\begin{array}{l}4^{\circ} \text { ano, um aluno com paralisia cerebral que realizava } \\
\text { movimentos com maior facilidade nos membros do lado } \\
\text { direito }\end{array}$ \\
\hline $\begin{array}{l}5^{\circ} \text { ano, um aluno com paralisia cerebral que, na Educaçáo } \\
\text { Física, usava um andador do tipo fraldáo, tinha movi- } \\
\text { mentação dos membros inferiores e, hipótese diagnóstica } \\
\text { de baixa visão }\end{array}$ \\
\hline
\end{tabular}

Quadro 1 -Turmas selecionadas e características dos alunos.

Fonte: elaboração própria.

Utilizou-se uma filmadora afixada em um tripé, na diagonal da quadra e a pesquisadora rotava o equipamento para a direção necessária. As aulas foram filmadas na íntegra, com duração de 50 minutos, e o foco deveria ser o professor de Educação Física e o aluno com deficiência ou o aluno com autismo.

\subsection{ANÁlise E TRATAMENTO DOS DADOS}

A análise e o tratamento dos dados foram realizados separadamente para cada professor. As filmagens foram assistidas na íntegra e realizou-se a identificação e a seleção de excertos (partes extraídas de um todo) tendo como critério a busca por situações que exemplificassem dificuldade e sucesso dos dois professores para criar condições favoráveis à inclusão de alunos 
com deficiência e os alunos com autismo. Os excertos selecionados foram categorizados em temas, conforme os pressupostos da análise de conteúdo (BARDIN, 2012).

Com relação à análise externa, julgou-se que as pessoas mais indicadas para pontuar as situaçóes de dificuldade e de sucesso identificadas na pesquisa eram os próprios professores de Educação Física, pois, enquanto "nativos" da escola teriam mais propriedade para argumentar e julgar as cenas advindas da própria prática. Dessa forma, em etapa posterior da pesquisa - formação prática - os excertos foram apresentados aos dois professores, separadamente para P1 e P2, e por meio da reflexão a partir do vídeo eles analisaram se de fato cada excerto representava uma dificuldade ou um sucesso.

Os excertos já selecionados e categorizados foram submetidos a um tratamento com o objetivo de identificar como as informaçóes contidas em cada um desses excertos poderiam direcionar o planejamento da formaçáo continuada, alvo da pesquisa maior do qual o presente estudo faz parte.

O tratamento dos excertos foi realizado em dois passos: 1) descrever se o excerto representava uma situação de sucesso ou de dificuldade e qual a dificuldade ou sucesso, e 2) detalhar como a situação poderia colaborar com o planejamento da formação continuada, seja em conteúdo para a formação teórica ou em açóes para a formação prática.

\section{Resultados}

Os resultados serão apresentados e discutidos separadamente para cada professor.

\subsection{Situaçóes de dificuldade e de sucesso de P1}

A partir das filmagens das 12 aulas de P1 foram identificados excertos característicos de três temas: 1) situação de sucesso; 2) dificuldade relacionada à estratégia de ensino, e 3) dificuldade relacionada à falta de ação propositiva em relação à inclusão.

O Tema 1 contemplou as situaçóes de sucesso de P1 frente à inclusão escolar dos alunos com deficiência e alunos com autismo, em diferentes aspectos, como exemplificado no Quadro 2.

1) Prestar assistência física à aluna com atraso no desenvolvimento neuropsicomotor e que usava andador, durante os movimentos do alongamento e atividades motoras de maior complexidade;

2) Oferecer feedback positivo ao aluno com paralisia cerebral após a realização da atividade;

3) Explicar a atividade por meio da instrução verbal e da demonstraçáo, e oferecer explicaçôes individualizadas quando necessário;

4) Selecionar o conteúdo das aulas com base no lúdico, na participação e não na competição;

5) Adaptar a regra: em uma atividade de driblar a bola de basquetebol, uma colega empurrou a cadeira de rodas e a aluna com atraso no desenvolvimento neuropsicomotor arremessou a bola ao cháo para quicar e ir até a mão de P1, que devolvia a bola com o mesmo movimento; ao invés de soletrar a palavra, o aluno com paralisia cerebral pode falar as sílabas;

6) Romper a barreira da "passividade do aluno", estimulando-o a participar;

7) Permitir que os ajudante naturais auxiliassem os alunos com deficiência;

Quadro 2 - Situaçóes de sucesso.

Fonte: elaboração própria. 
Ao pesquisar sobre o tema inclusão escolar em aulas de Educação Física fica evidente que existem consideráveis informaçóes sobre as dificuldades dos professores (FIORINI; MANZINI, 2014). No entanto, os resultados apresentados no Quadro 2 demonstram que, na prática, P1 também vivenciava situações de sucesso e,por meio delas, algumas dificuldades específicas eram superadas; o professor conseguia respostas a pergunta que ele mesmo se fazia: "o que e como ensinar?".

É importante destacar que as situaçôes de sucesso não foram identificadas exclusivamente na turma em que P1 relatou como "sem dificuldade para incluir", mas também foram identificadas nas aulas das turmas que ele havia apontado como "com dificuldade para incluir". Ao analisar essas situaçóes de sucesso, verifica-se que elas corroboram a literatura, uma vez que P1: adequou a instrução (LIEBERMAN; HOUSTON - WILSON, 2002; NABEIRO, 2010), selecionou conteúdos que permitiram a participação dos alunos com e sem deficiência na mesma aula, baseado no lúdico (MUNSTER; AVERSAN, 2011); adaptou as regras (BEZERRA, 2010; WINNICK, 2004) e utilizou os ajudantes naturais (NABEIRO, 2010).

De modo geral, o Tema 1 contribuirá com o planejamento da formação continuada no sentido de que será necessário elaborar uma formação que permita aos professores refletir sobre a própria atuação, assistindo aos trechos de sua aula, e que possa identificar que a sua prática docente não era composta apenas por dificuldades, mas que havia sucesso.

No Tema 2 serão arroladas as dificuldades relacionadas à estratégia de ensino, tal como descrito no Quadro 3.
1) Dificuldade em dispor os alunos na atividade de modo a conseguir explicar a atividade e evitar dispersóes;
2) Dificuldade para selecionar o recurso mais adequado ou realizar adaptaçóes frente ao materiais disponíveis;
3) Necessidade de treinar os ajudantes naturais com dicas da melhor maneira de ajudar o colega com deficiência;

Quadro 3-Situações de dificuldade em relação à estratégia de ensino.

Fonte: elaboração própria.

O P1 vivenciava situaçóes de dificuldade em estabelecer estratégias para partes específicas da aula. Sobre dispor os alunos, P1 encontrava dificuldades no arranjo deles de modo que pudesse completar a explicação e a demonstração da atividade sem que parte dos alunos se dispersasse e comprometesse a instrução. A importância no estabelecimento de estratégias para organizar os alunos foi destacada por Bezerra (2010), sendo que a distribuição dos alunos na quadra é uma das estratégias necessárias no momento inicial das aulas e a mais indicada para o encaminhamento do ensino inclusivo.

A estratégia é uma ação do professor, que muitas vezes, faz uso de um recurso pedagógico para alcançar um objetivo de ensino ou de avaliação (MANZINI, 2010). O P1 encontrou dificuldades, justamente, na seleção e adaptação desse recurso. Os materiais utilizados pelo professor eram os recursos tradicionais da Educação Física e disponíveis na escola. Dessa forma, ao invés de selecionar um recurso pedagógico a partir das características e potencialidades dos alunos e, que de fato, fosse mais adequado, P1 escolhia-o dentre as opçóes que havia na escola. Assim, se para um aluno com paralisia cerebral era mais adequada uma bola leve e maior, utilizava-se a bola de voleibol "não tão cheia". 
Outra dificuldade foi em relação aos ajudantes naturais. A presença desses alunos foi mencionada, anteriormente, como uma situação de sucesso, uma vez que ocorria de forma espontânea e voluntária. A dificuldade originou-se da necessidade desses voluntários saberem a melhor forma de auxiliar o colega com deficiência. $\mathrm{O}$ colega tutor treinado é uma estratégia que pode ser utilizada para dinamizar a aula de Educação Física no contexto da inclusão escolar e, ainda, diminuir o preconceito, pois apresenta informaçóes importantes para os alunos sem deficiência sobre as necessidades e as capacidades dos alunos com deficiência (FIORINI; NABEIRO, 2013).

As dificuldades inerentes ao Tema 2 sinalizaram conteúdos para a formação continuada em nível teórico, como: a) tipos de instrução;b) adaptações; c) a maneira de selecionar e adaptar um recurso diante das necessidades e potencialidades dos alunos; como apresentar esse recurso ao aluno; d) quem pode ser e como treinar os tutores. E, em etapa prática da formação, realizar o treinamento dos colegas tutores.

No Tema 3 foram agrupados os excertos de filmagens que indicaram as dificuldades de P1 para incluir os alunos com deficiência e os alunos com autismo em função da falta de ação propositiva em relação à inclusão, como detalhado no Quadro 4.

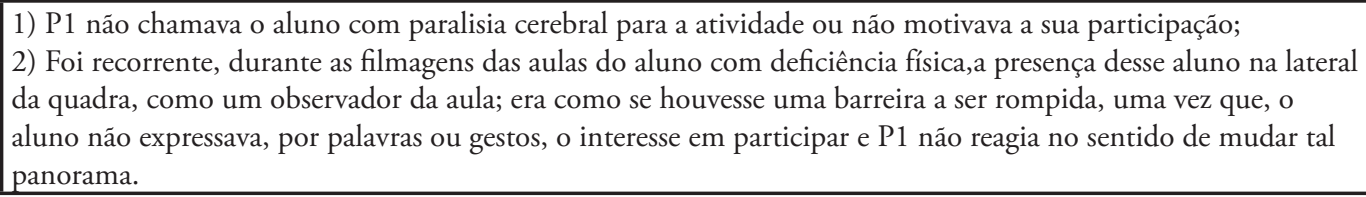

Quadro 4-Situaçóes de dificuldade em relação à falta de ação propositiva em relação à inclusão. Fonte: elaboração própria.

Por meio das filmagens identificou-se que, em três das quatro aulas filmadas, P1 não apresentou açóes para mudar a situação de não participação do aluno, apoiando-se no discurso de “aluno passivo". Para Rizzo (1984), as atitudes podem ser influenciadas pelo tipo deficiência, experiência de ensino para aluno com deficiência, conhecimento da deficiência. Quando, na última aula registrada, P1 afastou-se do antigo discurso e mudou o seu modo de olhar para aquele aluno, não o vendo como "passivo", mas como um aluno que podia participar e que tinha potencial, estabeleceram-se açóes propositivas favoráveis à inclusão, pelo menos naquela aula. $\mathrm{O}$ que se registrou foi um avanço de P1 na medida em que estabeleceu estratégias para trazê-lo para a atividade e mantê-lo participando dela. Assim como foi destacado por Dupoux, Wolman e Estrada (2005) e Elliot (2008), professores de Educação Física com atitude positiva para a inclusão escolar fornecem mais prática para todos os seus alunos.

Desse modo, durante em etapa teórica da formação continuada, haverá a necessidade de abordar o tema atitudes e características do professor de Educaçáo Física no contexto da inclusão educacional, assim como, precisará ser um assunto recorrente na etapa prática.

\subsection{SituaÇóEs de DifiCuldade E de SUCESSO DE P2}

A partir das filmagens das 16 aulas de P2 foram identificados excertos característicos de seis temas: 1) situaçóes de sucesso; 2) dificuldade relacionada à seleção do conteúdo; 3) di- 
ficuldade relacionada à estratégia de ensino; 4) dificuldade relacionada ao recurso pedagógico; 5) dificuldade relacionada à falta de ação propositiva em relação à inclusão, e 6) possibilidades e dificuldades relacionadas à presença da professora de sala durante a aula de Educação Física.

O Tema 1 contemplou as situações de sucesso de P2 para os incluir os alunos com deficiência e os alunos com autismo nas turmas acompanhadas. As açóes bem sucedidas aconteceram em diferentes aspectos, como exposto no Quadro 5.
1) Reforçar as explicações antes do início da atividade e quando necessário fazer explicações individualizadas;
2) Ter uma conduta de tentar manter a atenção dos alunos com autismo, isso porque, sempre chamava-os de volta para a atividade;
3) Manter a rotina dos exercícios do alongamento, a qual o aluno com autismo conhecia e executava;
4) Valorizar as estratégias do aluno com paralisia cerebral que se comunicava por meio de gestos e sinais e P2 os compreendia;
5) Adaptar as regras oficiais.

Quadro 5 - Situaçóes de sucesso.

Fonte: elaboração própria.

As situaçóes de sucesso foram identificadas nas filmagens das quatro turmas acompanhadas, as mesmas que haviam sido denominadas por P2 como "com dificuldade para incluir". Eram situaçóes corriqueiras e que favoreciam não só os alunos com deficiência e alunos autismo, mas também os alunos sem deficiência, principalmente, em relação à instrução e à adaptação das regras. Para Bezerra (2010), no momento inicial de uma aula, o encaminhamento que o professor atribui à instrução determina as possibilidades de sucesso da aula, sendo como possibilidade, a orientação verbal, a demonstração e a assistência física (LIEBERMAN; HOUSTON - WILSON, 2002; NABEIRO, 2010). Já a adaptação das regras é uma necessidade comum à Educação Física para possibilitar uma maior participação dos alunos mesmo em turmas que não haja alunos com deficiência e alunos com autismo. Trata-se de adaptar ou alterar as regras originalmente estabelecidas (WINNICK, 2004).

Os excertos das filmagens com situações de sucesso poderão ser utilizadas tanto na etapa teórica quanto na etapa prática da formação, sempre para permitir a reflexão sobre a prática de professores de Educação Física quando há alunos com deficiência e alunos com autismo matriculados no Ensino Regular.

$\mathrm{O}$ Tema 2 faz referência às dificuldades apresentadas por P2 em função da escolha do conteúdo, como apresentado no Quadro 6.
1) Durante as filmagens das aulas, o conteúdo predominante foi o competitivo, de tal forma que estava imbrin- cado em alguns comportamentos dos alunos querer saber quem ganhou ou se desentender pelo placar final da atividade;
2) Uma consequência da aula competitiva foi quando P2 precisou lembrar aos alunos que o aluno com deficiên- cia também era da equipe e que o deixassem fazer a atividade uma vez;
3) Ausência de vínculo entre uma aula e outra;

Quadro 6 - Situações de dificuldade em relação do conteúdo.

Fonte: elaboração própria.

A Educação Física engloba dança, educação, esporte, ginástica, jogo, lutas, recreação, qualidade de vida (BRASIL, 1998). Apesar dessa variedade de possibilidades, a Educação Física 
Escolar ainda apresenta fortes traços da cultura competitivista e esportivizadora, que significa, entre outras coisas, enfatizar o mais forte, o mais rápido, o mais habilidoso. Em contrapartida, a Educação Física Escolar precisaria ser aquela que prima pelo universo das potencialidades de todos os alunos. Especificamente sobre P2, a opçáo pela competiçáo pode estar relacionada à formação e às experiências vivenciadas pelo professor, que tende a reproduzir as suas concepçóes. Ressalta-se que P2 apresentava um histórico pessoal e profissional relacionado ao rendimento.

É importante salientar que a falta de vínculo entre as atividades era uma dificuldade imbricada à didática de $\mathrm{P} 2$, não se relacionando especificamente aos alunos com deficiência e alunos com autismo. Uma informação que corrobora essa afirmação foi o fato de P1 e P2 não possuírem um planejamento anual, semestral ou bimestral, mas a rotina de elaborar semanários, o que, talvez, possa ter colaborado para a falta de vínculo entre as atividades.

As dificuldades atribuídas ao Tema 3 remetem à necessidade de elaborar uma formação continuada que discuta sobre a seleção de conteúdos, as opções de jogos, as atividades e esportes para turmas regulares em que há alunos-alvo da Educação Especial.

No Tema 3 destacam-se as dificuldades encontradas por P2 devido à estratégia de ensino, como exemplificado no Quadro 7.
1) Na explicaçáo das atividades: um dos alunos acompanhados apresentava, segundo relatos de P2, uma baixa- -visão, mesmo ciente disso, por vezes, P2 explicou a atividade de costas para esse aluno, referindo-se a lugares por meio de expressóes como, aqui, ali, para lá; sugeria que esse aluno se orientasse pelas cores das linhas da quadra;
2) No caso da turma em que havia um aluno com autismo era a mesma instruçáo para todos e de modo verbal;
3) Alto nível de complexidade das informaçóes passadas, especificamente para o $1^{\circ}$ ano;

Quadro 7 - Situaçóes de dificuldade em relação à estratégia de ensino.

Fonte: elaboração própria.

As dificuldades desse tema podem ser resumidas em dificuldades relacionadas à como instruir os alunos. A instrução é uma das variáveis que pode ser adaptada para tornar uma atividade acessível às pessoas com deficiência (NABEIRO, 2010; LIEBERMAN; HOUSTON - WILSON, 2002; SHERRIL, 1998). No caso do aluno com hipótese de baixa-visão, certas barreiras da aprendizagem estão relacionadas aos componentes da linguagem no momento de exposições orais, como as coordenadas espaço-temporais que podem dificultar a compreensão (LAVARDA; BIDARRA, 2007). Era justamente o que ocorria, pois, em função de uma explicação não tão adequada em termos de linguagem, o aluno apresentava-se desorientado durante as atividades.

No que se refere à explicação das atividades para o aluno com autismo, a dificuldade agravou-se em virtude de um contexto de aula no qual P2 não apresentava certeza e segurança em suas açôes, uma vez que o autismo ainda gerava dúvidas e inquietaçóes.

Ao analisar as filmagens de P2, especificamente sobre a instrução, duas questóes se sobressaíram: quais elementos devem conter a explicação de uma atividade quando há um aluno com autismo? Só a explicação verbal e geral para a turma é suficiente? Reconhecendo a heterogeneidade dos alunos e as variaçóes do espectro autista e, mais ainda, sem a pretensão de encerrar essa discussão ou de generalizar o modo de ensinar alunos com autismo, ressalta-se 
alguns apontamentos de Seabra Júnior et al. (2015), sobre o que professor de Educação Física poderia considerar ao explicar atividades para alunos com autismo: 1) o professor tem a atenção do aluno antes de dar a instrução? 2) a linguagem verbal é específica para o nível de compreensão dos alunos? 3) a instrução verbal é acompanhada de gestos que favoreçam o entendimento da tarefa? 4) as dicas são específicas ao estilo e nível de aprendizagem do aluno?

Em síntese, a quantidade de informaçóes oferecidas ao aluno deva estar ligada à sua capacidade de realizar um movimento (SEABRA JÚNIOR; MANZINI, 2008). O uso de linguagem acessível, compreensível e objetiva constitui-se regras básicas para a instrução (BEZERRA, 2010).

Pontua-se que, as dificuldades descritas no Tema 4 subsidiarão o planejamento da formação continuada no sentido em que demonstraram a pertinência em abordar a questão da linguagem e da instrução das atividades.

O Tema 4 emergiu das dificuldades encontradas por P2 em relação à seleção e ao uso do recurso pedagógico, como exposto no Quadro 8.

1) Utilizou uma bola branca e sem som com o aluno com hipótese diagnóstica de baixa-visão;

2) Realizou uma atividade com o uso de bolinhas de tênis de mesa, que deveriam ser passadas de mão em mão,

na turma em que estava o aluno com paralisia cerebral e que tinha a mão direita no padrão de flexão;

Quadro 8 - Situações de dificuldade em relação à seleção e ao uso do recurso pedagógico Fonte: elaboração própria.

O professor P2 utilizava os recursos tradicionais da Educação Física e disponíveis na escola, mas em diversas situaçóes esses recursos não foram suficientes para promover a funcionalidade dos alunos com deficiência física e visual. Um dos elementos das aulas de Educação Física que é passível de modificaçóes é o recurso pedagógico (NABEIRO, 2010; LIEBERMAN; HOUSTON - WILSON, 2002; SHERRIL, 1998). Cabe aqui salientar que, a disponibilidade de recursos adequados ou já adaptados aos alunos com deficiência pode não ser o único fator de dificuldade. É preciso considerar o desconhecimento do professor de Educação Física sobre quais recursos utilizar, como utilizar e o quê e como adaptar.

Para o aluno com paralisia cerebral e hipótese de baixa-visão foi identificado que a maior necessidade era selecionar ou adaptar recursos em função da baixa-visão. Destaca-se que, a participação desse aluno era bastante comprometida tanto em função dos recursos pedagógicos que não estavam adequados, quanto em função da instrução das atividades, que frisavam sempre informaçóes visuais. No exemplo da bola branca e sem som, a sugestão era que P2 a torna-se perceptível auditivamente, inserindo guizos ou amarrando sacos plásticos e, utilizasse bola laranja, azul ou amarela para melhorar o contrate (SEABRA JÚNIOR; MANZINI, 2008).

Vislumbra-se que, para a formação continuada, mais do que ofertar recursos e materiais didáticos aos professores de Educação Física, será preciso que de modo teórico e prático eles aprendam a selecionar e adaptar um recurso a partir das características e potencialidades dos alunos, e quais variáveis podem ser manipuladas.

O Tema 5 caracterizou-se pelas dificuldades relacionadas à falta de ação propositiva em relação à inclusão, como exposto no Quadro 9. 
Em relação ao aluno com paralisia cerebral e hipótese de baixa-visão:

1) P2, nos momentos em que esse aluno não participação na aula ou permanecia na lateral da quadra, não motivava a participação, demonstrando, ainda, pouco comunicação com esse aluno;

2) A ação de P2 era estimulada ou uma consequência de uma açáo da professora de sala, que motivava o aluno;

Quadro 9-Situaçóes de dificuldade em relação à falta de ação propositiva em relação à inclusão. Fonte: elaboração própria.

As açóes de P2 eram influenciadas pelo contexto das aulas e pelas demais situaçóes de dificuldades para incluir, especificamente, o aluno com paralisia cerebral e hipótese de baixa-visão. A ação de P2 foi um ponto de dificuldade, em virtude de não agir no sentido de mudar o contexto de "desmotivação do aluno". Os estímulos e motivaçóes ocorriam por parte da professora de sala que, com uma visão mais otimista, acompanhava-o e incentivava-o à pelo menos tentar.

O Tema 6 contemplou possibilidades e dificuldades relacionadas à presença da professora de sala durante a aula de Educação Física, como apresentado no Quadro 10.
1) Possibilidades: a professora de sala participou da atividade junto com a turma e auxiliou a empurrar a cadeira de rodas do aluno, estimulava o aluno com deficiência a continuar fazer a atividade e elogiava;
2) Dificuldade: era a professora de sala quem corrigia os alunos, fazia a contagem no alongamento, fazia a con- tagem dos pontos das equipes, era ela quem motivava o aluno com autismo durante todas as atividades, tendo havido algumas ocasiōes em que ela fez a atividade no lugar do aluno;

Quadro 10 - Possibilidades e dificuldades relacionadas ao fato da professora de sala acompanhar a Educação Física.

Fonte: elaboração própria.

Devido ao fato de as professoras de sala do Ensino Fundamental, do $1^{\circ}$ ao $5^{\circ}$ ano, serem as responsáveis pela turma, elas deveriam acompanhar as aulas de Educação Física. Sobre isso, o que se registrou no período das filmagens foi um panorama tanto de possibilidades quanto de dificuldades. As possibilidades em relação à presença da professora de sala foram identificadas em três das quatro turmas que tiveram as aulas filmadas. Nessas turmas, as professoras apresentavam um perfil amigável e colaborativo, no sentido de observar a aula sem participar ou participar sem ocupar as funçóes e a responsabilidade que eram de P2 e, ajudavam, quando preciso, na manutenção da disciplina junto aos alunos ou especificamente com os alunos com deficiência, estimulando-os.

As dificuldades relacionadas à presença da professora de sala foram identificadas, especificamente, nos registros de uma dentre as quatro turmas, no $1^{\circ}$ ano em que estava matriculado o aluno com autismo/paralisia cerebral/Síndrome de Dand Walker. O perfil da professora de sala era mais invasivo, no sentido de que corrigia os alunos, fazia a contagem no alongamento, fazia a contagem dos pontos das equipes, era ela a professora que motivava o aluno com deficiência e acompanhava o aluno com deficiência durante todas as atividades, tendo havido algumas ocasióes em que ela fez a atividade no lugar do aluno. 
Especificamente sobre a formação continuada para os professores de Educação Física, será preciso abordar a temática "Questóes administrativo-escolares", buscando esclarecimentos sobre a obrigatoriedade ou a recomendaçáo para que o professor de sala acompanhe as aulas de Educação Física. Outro caminho será traçar possibilidades para que a presença da professora da sala seja um ponto de apoio para ao professor de Educação Física e colabora para a criação de condiçóes favoráveis à inclusão.

\section{Conclusóes}

Conclui-se que, os dois professores de Educação Física encontravam dificuldades, por diversos motivos, para criar condiçôes favoráveis a inclusão dos alunos com deficiência e alunos com autismo, seja em função das estratégias de ensino, dos recursos pedagógicos, da seleção de conteúdos, da presença da professora de sala ou da falta de ações propositivas em relação à inclusão. Mas, a inclusão escolar não ocasionou apenas dificuldades para P1 e P2, pelo contrário, nas aulas de Educação Física também eram vivenciadas inúmeras situaçóes de sucesso e, o mais curioso, nas turmas que ambos os professores relataram como "com dificuldades para incluir".

Além de sucessos e dificuldades, a prática dos professores de Educação Física em turmas regulares com alunos com deficiência e alunos com autismo apresentou três aspectos que embasavam o desenvolvimento das aulas: 1) o perfil e as experiências prévias de cada professor; 2) o tipo de deficiência ou de transtorno e o conhecimento sobre eles, e 3) a empatia professor - aluno e aluno - aula de Educação Física, sendo que o contexto e a dinâmica das aulas foram mais favoráveis à inclusão quando o professor "olhava” para o aluno com deficiência ou com transtorno e "enxergava" possibilidades e capacidades, ao invés de focar na limitação e, quando o próprio aluno apresentava interesse pelas aulas e motivação em participar.

Retomando o objetivo do estudo, conclui-se que as situaçóes de dificuldade e de sucesso identificadas nas aulas dos dois professores de Educação Física subsidiarão a elaboração da formação continuada por terem indicado três aspectos essenciais à formação pretendida:

1) Alguns das dificuldades identificadas eram reincidentes das já identificadas no estudo anterior por meio de Grupo Focal (FIORINI; MANZINI, 2014) e, dessa maneira, reforçaram a necessidade de abordar teórica e praticamente tópicos como: ajudantes naturais acompanhando os alunos com deficiência; a necessidade de estratégias de ensino adequadas ou adaptadas; a seleção, adaptação e uso dos recursos pedagógicos e, a presença da professora de sala nas aulas de Educação Física;

2) Por meio das filmagens foi possível conhecer o contexto vivenciado pelos professores, detalhar as dificuldades e compreender como elas ocorriam. Em consequência, pôde-se avançar no planejamento da formaçáo continuada, isso porque se evidenciou que as dificuldades iam além do "desconhecimento" sobre as características das deficiências, síndromes e transtornos, mas estavam precisamente na necessidade de saber como ensinar os alunos com deficiência e alunos com autismo matriculados no Ensino Regular, isso é: o que devo fazer? O que posso fazer? O que devo evitar? Quais as possibilidades? Como as estratégias e os recursos pedagógicos podem auxiliar? Quais podem ser essas estratégias e recursos pedagógicos? 
3) Outros dois conteúdos a serem integrados à formação continuada foram identificados, e não haviam sido relatados no Grupo Focal, sendo eles a falta de ações propositivas em relação à inclusão e as situaçóes de sucesso. Especificamente sobre as situaçóes de sucesso, os excertos das filmagens poderão ser utilizados como subsídio para a reflexão sobre a própria prática docente quando há alunos com deficiência e alunos com autismo. Essa reflexão tenderá ser, tanto coletiva durante a formação teórica para o grupo de professores de Educação Física, quanto individual que ocorrerá na formação prática, por meio da apresentação desses excertos.

Nessa direção, será preciso planejar uma formação continuada para os professores de Educação Física que, por um lado, atenda às necessidades e auxilie na minimização das dificuldades e, por outro lado, valorize as situaçóes de sucesso que vinham ocorrendo.

\section{REFERÊNCIAS}

ALVES, M. L. T.; DUARTE, E. A percepção dos alunos com deficiência sobre a sua inclusão nas aulas de educação física escolar: um estudo de caso. Rev.Bras. Educ. Fís. Esporte, São Paulo, v.28, n.2, p.329338, 2014.

APA. AMERICAN PSYCHIATRY ASSOCIATION. Manual de diagnóstico estatístico das perturbaçóes mentais: DSM-IV-TR. Lisboa: Climepsi, 2002.

BARDIN, L. Análise de conteúdo. Edição Revisada e Ampliada. Lisboa: Ediçôes 70, 2012.

BEZERRA, A. F. S. Estratégias para o ensino inclusivo de alunos com deficiência nas aulas de educação física. 2010. 108f. Tese (Doutorado em Educação) - Faculdade de Filosofia e Ciências, Universidade Estadual Paulista, Marília, 2010.

BRASIL. Comitê de Ajudas Técnicas. Ata da Reunião VII, de dezembro de 2007 do Comitê de Ajudas Técnicas. Secretaria Especial dos Direitos Humanos da Presidência da República (CORDE/SEDH/ PR), 2007. Disponível em: <http://www.mj.gov.br/corde/arquivos/doc/Ata\%20III\%2019\%20e\%20 20\%20abril2007.doc>Acesso em: 20 jul. 2015.

BRASIL. Secretaria de Educação fundamental. Parâmetros curriculares nacionais. Brasília, DF: MEC/ SEF, 1998.

BUENO, S. T.; RESA, J.A.Z. Educacion fisica para niños y ninâs com necessidades educativas especiales. Malaga: EdicionesAljibe, 1995.

CHICON, J. F. Inclusão na educação física escolar: construindo caminhos. 2005. 420f. Tese (Doutorado em Educação) - Faculdade de Educação da USP, São Paulo, 2005.

CHICON, J. F.; MENDES, K.A.M.O.; SÁ, M.G.C.S. Educação física e inclusão: a experiência na Escola Azul. Movimento, Porto Alegre, v.17, n.4, p.185-202, 2011.

CRAFT, D. H. A focus on inclusion in Physical Education. In: HENESSY, B. (Ed.). Physical Education source-book. Champaign: Human Kinetics, 1996.

DUPOUX, E.; WOLMAN, C.; ESTRADA, E. Teachers's attitudes toward integration of students with disabilities in Haiti and the United States.International Journal of Disability, v.52, n.1, p.43-58, 2005. 
ELLIOTT, S.The effect of teachers' attitude toward inclusion on the practice and success levels of children with and without disabilities in physical education. International Journal of Special Education, v.23, n.3, p.8-55, 2008.

FIORINI, M. L. S. Concepção do professor de educação física sobre a inclusão do aluno com deficiência. 2011. 143f. Dissertação (Mestrado em Educação) - Faculdade de Filosofia e Ciências, Universidade Estadual Paulista, Marília, 2011.

FIORINI, M. L. S.; NABEIRO, M. Um estudo sobre a intervenção com o professor de educação física para inclusão educacional do aluno com deficiência visual. Revista da Sobama, Marília, v.14, n.2, p-2126, 2013.

FIORINI, M.L.S.; MANZINI, E.J. Inclusão de alunos com deficiência na aula de educação física: identificando dificuldades, açôes e conteúdos para prover a formação do professor. Revista Brasileira de Educação Especial, Marília, v.20, n.3, p.387-404, 2014.

GORGATTI, M. G. Educação física escolar e inclusão: uma análise a partir do desenvolvimento motor e social de adolescentes com deficiência visual e das atitudes dos professores. 2005. 173f. Tese (Doutorado em Educação Física) - Escola de Educação Física e Esporte, Universidade de São Paulo, São Paulo, 2005.

JESUS, D.M.; EFFGEN, A.P.S. Formação docente e práticas pedagógicas: conexôes, possibilidades e tensôes. In: MIRANDA, T.G.; GALVÃO FILHO, T.A. (Org.). O professor e a educação inclusiva: formação, práticas e lugares. Salvador: EDUFBA, 2012.

LAVARDA, S. T. F.; BIDARRA, J. A dêixis como um "complicador/facilitador" no contexto cognitivo e lingüístico em ambiente educacional face aos alunos com deficiência visual. Revista Brasileira de Educação Especial, Marília, v.13, n.3, p.309-324, 2007.

LIEBERMAN, L. J.; HOUSTON - WILSON, C. Strategies for inclusion: a handbook for physical educators. Champaign: Human Kinetics, 2002.

MANZINI, E.J. Recurso pedagógico adaptado e estratégias para o ensino de alunos com deficiência física. In: MANZINI, E. J.; FUJISAWA, D. S. (Org.). Jogos e recursos para comunicação e ensino na educação especial. Marília: ABPEE, 2010. p.111-132.

MANZINI, E.J. Recursos pedagógicos para o ensino de alunos com paralisia cerebral. Revista Mensagem da APAE, v.36, n.84, p.17-21, 1999.

MANZINI, E. J.; DELIBERATO, D. Portal de ajudas técnicas: equipamento e material pedagógico para educação - recursos adaptados II. Brasília, DF: ABPEE/MEC/SEESP, 2007.

MANZINI, E.J.; ALBUQUERQUE, D.I.P. Tecnologia assistiva: enfocando a deficiência física. 2014. No prelo.

MARTINS, L.A.R. Reflexôes sobre a formação de professores com vistas a educação inclusiva. In: MIRANDA, T.G.; GALVÃO FILHO, T.A. (Org.). O professor e a educação inclusiva: formação, práticas e lugares. Salvador: EDUFBA, 2012.

MENEZES, A.R.S. A inclusão de alunos com autismo em escolas públicas de Angra dos Reis. In: NUNES, L.R.O.P.; WLATER, C.C.F. (Org.). Ensaios sobre autismo e deficiência múltipla. São Carlos: Marquezine \& Manzini; Marília: ABPEE, 2013. p.117-126.

MORLEY, D. et al. Inclusive physical education: teachers' views of including pupils with special educational needs and/or disabilities in physical education. European Physical Education Review, v.11, n.1, 2005. 
MUNSTER, M.A.V. Inclusão de estudantes com deficiências em programas de educação física: adaptaçóes curriculares e metodológicas. Revista da Sobama, Marília, v.14, n.2, p.27-34, 2013.

MUNSTER, M.A.V.; ALMEIDA, J.J.G. Um olhar sobre a inclusão de pessoas com deficiência em programas de atividade motora: do espelho ao caleidoscópio. In: RODRIGUES, D. (Org.). Atividade Motora Adaptada: a alegria do corpo. São Paulo: Artes Médicas, 2006. p.81-92.

MUNSTER, M.AV.; AVERSAN, T. Estratégias de sensibilização para a inclusão no contexto da educação física escolar. In: CHICON, J.F.; RODRIGUES, G.M. (Org.). Práticas pedagógicas e pesquisa em educação física escolar inclusiva. Vitória: EDUFES, 2011. p.169-189.

NABEIRO, M. O colega tutor nas aulas de educação física inclusiva. In: MENDES, E. G.;

ALMEIDA, M. A. (Org.). Das margens ao centro: perspectivas para as políticas e práticas educacionais no contexto da educação especial inclusiva. Araraquara: Junqueira \& Marin, 2010.

PALLA, A. C.; MAUERBERG-DECASTRO, E. de. Atitudes de professores e estudantes de educação física em relação ao ensino de alunos com deficiência em ambientes inclusivos. Revista da Sobama, Rio Claro, v.9, n.1, p. 25-34, 2004.

PEDRINELLI, V.J.; VERENGUER, R.C.G. Educação física adaptada: introdução ao universo das possibilidades. In: GREGUOL, M. (Org.). Atividade física adaptada. São Paulo: Manole, 2004.

PILETTI, A.C.C. Entre os fios e o manto: tecendo a inclusão escolar. São Paulo: Ediçóes Loyola, 2014.

RECHINELI, A.; PORTO, E. T. R.; MOREIRA, W. W. Corpos deficientes, eficientes e diferentes: uma visão a partir da educação física. Revista Brasileira de Educação Especial, Marília, v.14, n.2, p.293-310. 2008.

RIZZO, T. L. Attitudes of physical educators toward teaching handicapped pupils. Adapted Physical Activity Quarterly, Champaing, v.1, p.267-274, 1984.

RIZZO, T. L.; LAVAY, B. Inclusion: Why the confusion? Journal of Physical Education, Recreation and Dance, v.71, n.4, p. 32-36, 2000.

SANT'ANNA, F.M. et al. Planejamento de ensino e avaliação. 11.ed. Porto Alegre: Sagra Luzzato, 1998.

SEABRA JUNIOR, M. O. et al. O vínculo interpessoal como estratégia nas intervençôes com crianças autistas: um relato de experiência. In: COLVARA, L.D.; OLIVEIRA, J. B. B. de (Org.). Núcleos de Ensino da Unesp: artigos 2013. Sáo Paulo: Cultura Acadêmica, 2015, v.5, p. 77-86.

SEABRA JÚNIOR, M. O.; MANZINI, E. J. Recursos e estratégias para o ensino do aluno com deficiência visual na atividade física adaptada. Marília: ABPEE, 2008.

SHERRIL, C. Adapted physical activity, recreation and sport. cross disciplinary and lifespan. Madison: WCB Mc Graw-Hill, 1998.

SUPLINO, M. A inclusão de pessoas com autismo em escola regular: desafios e possibilidades. In: NUNES, L.R.O.P.; WALTER, C.C.F. (Org.). Ensaios sobre autismo e deficiência múltipla. São Carlos: Marquezine \& Manzini; Marília, ABPEE, 2013. p.161-170.

WINNICK, J. P. Organização e Gerenciamento de Programas. In: WINNICK, J. P. (Org.). Educação física e esportes adaptados. Barueri: Manole, 2004. p.21-36.

Recebido em: 13/03/2015

Reformulado em: 17/12/2015

Aprovado em: 18/12/2015 